\section{APIC/CBIC Relationship Clarified}

To the Editor:

As president of the Certification Board of Infection Control (CBIC), I am writing to clarify some information that was printed in a recent issue of Infection Control. ${ }^{1}$

The author states that "... Programs to certify ICPs would insure a minimum level of knowledge for all certified ICPs ..." This statement is correct. However, the statement, “. . . Certification would be one way to assure that all practitioners receive the same foundations ..." does not follow. The Certification process is not designed to assure that all practitioners receive the same foundations (or education), and there is no way that it can measure how or where ICPs obtained the knowledge they need to pass the examination. The Infection Control Certification examination tests for knowledge that is job-related. The Infection Control Certification examination is based, in part, on the 1982 Task Analysis of ICPs in hospitals (unpublished data) and questions developed from a variety of sources by a number of individuals. Consensus by the CBIC that the questions are appropriate for ICPs with a variety of educational backgrounds who meet the practice requirement of at least two years of full-time or part-time experience in infection control in a hospital is the final step in the preparation of the examination.

The statement " ... A certification program is now available through APIC ..." is not correct. The certification process was initiated by APIC in 1978 with the formation of the
APIC Certification Committee. In late 1981, the Certification Board of Infection Control (CBIC) was established as a separate agency charged with the responsibility of developing the certification examination. There is a strong link with APIC; that is, APIC has been very supportive of the certification process, the APIC Board of Directors appoints members to the CBIC, and APIC members are provided a reduced fee for the examination. However, CBIC is administratively and legally separate from APIC. The CBIC has its own by-laws, management structure and firm, and a direct contractual arrangement with the Psychological Corporation, the professional testing agency employed to administer the test and provide psychometric consultation for test question review and development.

Finally, the author considers that "APIC's certification program" provides for training in infection control. Please note that the CBIC does not engage in any training activities nor do its members participate in any training programs that are specifically designed to prepare test applicants for the examination. This activity is viewed by the CBIC as a direct conflict of interest. APIC has developed educational programs and materials for use in preparation for the Infection Control Certification examination, but these educational resources were developed independently of the CBIC.

The separation between the professional association and the certification board is a difficult concept. The CBIC has followed recommendations of the National Commission for Health Certifying Agencies (NCHCA) in estab- lishing its by-laws. This Agency strongly recommends such separation for legal and other reasons.

\section{REFERENCES}

1. Crow S: Training of personnel for infection control. Infect Control 1984; 5:38-40.

Gina Pugliese, RN, MSN
President, CBIC
Chicago, Illinois

Sue Crow, RN, MSN, the author of the article in question, offers her response.

Thank you for clarifying the different roles of the Association of Practitioners in Infection Control (APIC) and the Certification Board of Infection Control (CBIC). There are many Infection Control Practitioners who do not know the definitive differentiation between these two organizations and you certainly have made this distinction clear.

Sue Crow, RN, MSN Nurse Epidemiologist Louisiana State University Shreveport, Louisiana

\section{Criteria for Membership in SHEA Questioned}

To the Editor:

The Editorial "Why SHEA" in a recent issue of Infection Control summarizes many organizational development questions quite well.

However, I cannot help but come away from it feeling as if "What is SHEA" were the real message. It is clear that SHEA was founded by aca- 